Pediat. Res. 9: 157 (1975)

\title{
Editorial: The Passing of the Torch
}

In ancient Greece the passing of the torch represented an unbroken succession of runners, each passing a light onto the next, heading toward a final goal. This act also symbolized the passage of responsibility. With this volume of Pediatric Research the torch has been passed and with it is transmitted the hopes and aspirations of a journal.

The Journal was conceived twelve years ago by a number of individuals with the expressed purpose of promoting the health of children through effective scholarship and the communication of knowledge among scientific disciplines. Over this period the Journal has faithfully adhered to these goals under the adroit leadership of Dr. Charles U. Lowe.

After a difficult delivery the infant Journal was beset with a number of complications which would have discouraged a less dedicated man. Dr. Lowe, with singular devotion and resolute perseverance, has nurtured the Journal up to its approaching adolescence. Buttressed by his driving energies and elegance of style, Dr. Lowe and his associates on both sides of the Atlantic Ocean melded a diversity of interests into a single viable enterprise of which our societies can be proud.

In the future Pediatric Research will undoubtedly face additional challenges, such as the uncertainty of the funding of research, the priority of its direction, and ethical issues concerned with the conduct of pediatric investigation. Nonetheless, the needs for continued research in pediatrics and for effective communication of research ideas continue and are ever expanding.

It is the pledge of the editors to maintain the high ideals of quality and fairness established under the stewardship of Dr. Lowe and to build upon the firm foundation laid by him. Just as the light from the ancient torch signified a universality of purpose, the international theme of the Journal is unique among pediatric chronicles. Moreover, it promotes the highest of human values through the expression of a variety of pediatric societies concerned with child health throughout the world. It is this expressed concern for the young which transcends all barriers of language or differences in perspective and rallies a mutual understanding around the focal point of the child. It is our hope to encourage continued communication with our colleagues across the seas, to exchange knowledge with them, and to encourage younger investigators in all lands.

Those of us who have known Dr. Lowe more in timately owe him a special debt of gratitude for his stimulation and guidance in our medical careers. All who have known him have been inspired by his deep commitment to improve child health. In his new role as Special Assistant for Pediatric Affairs, Office of the Assistant Secretary for Health, Department of Health Education and Welfare, he assumes the highest official position held by a child health worker in the executive branch and fills a long-standing void as a spokesman for children. We wish him the best in his new assignment and are confident that he will continue to provide the leadership for the health of children that he brought to his former roles. It is our hope that in the passing of the torch, this limb of the race will be well run illuminated by the light which has been passed on to us.

The Editorial Board Pediatric Research 